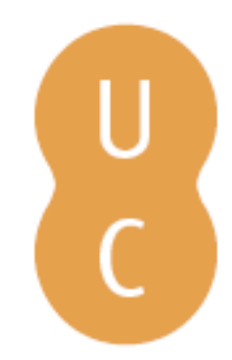

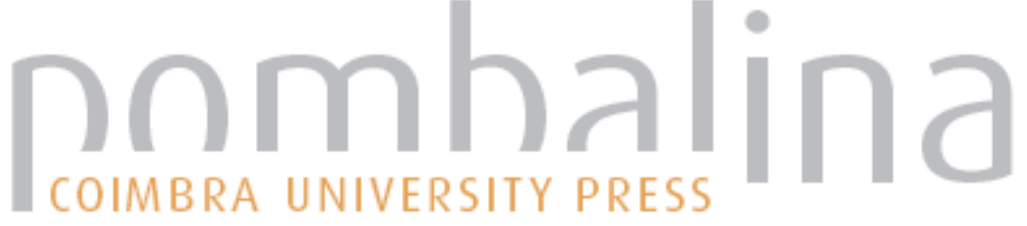

\section{O cinema ao serviço da ciência}
Autor(es):
Cunha, Paulo
Publicado por: Imprensa da Universidade de Coimbra
URL persistente:
URI:http://hdl.handle.net/10316.2/32397
DOI:
DOI:http://dx.doi.org/10.14195/978-989-26-0469-5_14

Accessed : $\quad$ 26-Apr-2023 16:13:19

A navegação consulta e descarregamento dos títulos inseridos nas Bibliotecas Digitais UC Digitalis, UC Pombalina e UC Impactum, pressupõem a aceitação plena e sem reservas dos Termos e Condições de Uso destas Bibliotecas Digitais, disponíveis em https://digitalis.uc.pt/pt-pt/termos.

Conforme exposto nos referidos Termos e Condições de Uso, o descarregamento de títulos de acesso restrito requer uma licença válida de autorização devendo o utilizador aceder ao(s) documento(s) a partir de um endereço de IP da instituição detentora da supramencionada licença.

Ao utilizador é apenas permitido o descarregamento para uso pessoal, pelo que o emprego do(s) título(s) descarregado(s) para outro fim, designadamente comercial, carece de autorização do respetivo autor ou editor da obra.

Na medida em que todas as obras da UC Digitalis se encontram protegidas pelo Código do Direito de Autor e Direitos Conexos e demais legislação aplicável, toda a cópia, parcial ou total, deste documento, nos casos em que é legalmente admitida, deverá conter ou fazer-se acompanhar por este aviso. 
Ana Leunar Pereira João Rui Pita

[ Coordenaçä̃ ]
Rotas da Natureza

Cientistas

Viagens

Expedifgũes

Instituip̧ües

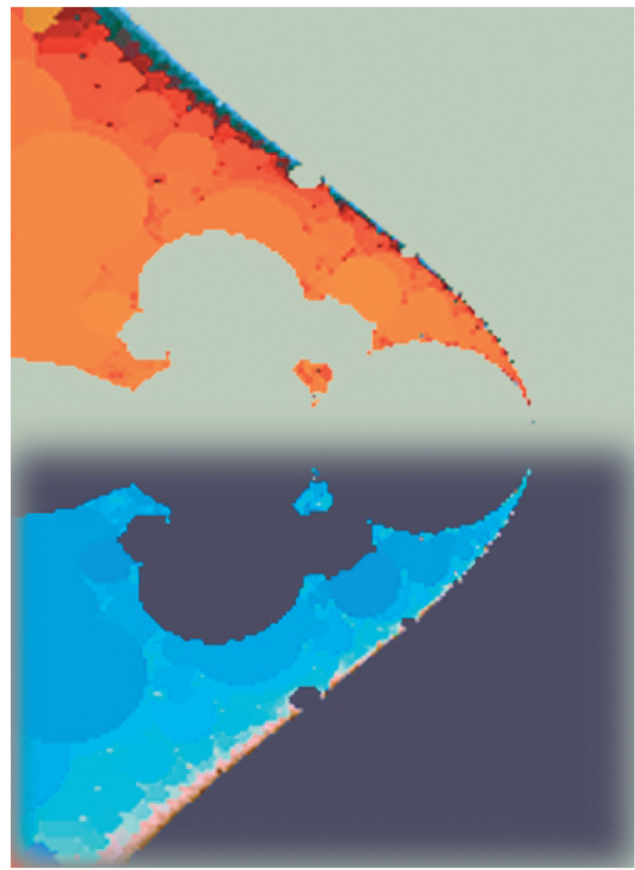




\section{Coordenaçáo Científica da Colecção Ciências e Culturas}

João Rui Pita e Ana Leonor Pereira

Os originais enviados são sujeitos a apreciação científica por referees

\section{Coordenação Editorial}

Maria João Padez Ferreira de Castro

\section{Edição}

Imprensa da Universidade de Coimbra

Email:impresauc@ci.uc.pt

URL: http://www.imp.uc.pt • Normas de publicação de colecçôes

\section{Design}

António Barros

Pré-Impressáo

António Resende

Imprensa da Universidade de Coimbra

\section{Capa}

António Barros, com imagem de E. M. de Melo e Castro, 2003 [Fractal original gerado no Fractint com tratamento no Photoshop 7.0]; Cortesia: António Barros

Impressão e Acabamento

SerSilito • Maia

\section{ISBN}

978-989-8074-12-6

\section{Depósito Legal}

Obra publicada com a colaboraçáo de:
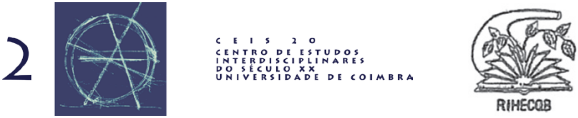

Obra publicada com o apoio de:

FCT Fundação para a Ciência e a Tecnologia

MINISTÉRIO DA CIÊNCIA, TECNOLOGIA E ENSINO SUPERTOR Portug

Programa Operacional Ciência, Tecnologia, Inovação do Quadro Comunitário de Apoio III
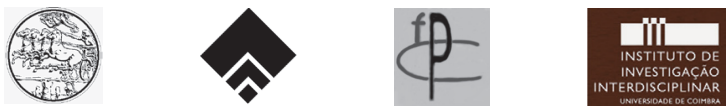

\section{Baxter}

(c) 2006, Imprensa da Universidade de Coimbra 
João Rui Pita

Ana Leonar Pereira

(Courdenação)

Rotas da Natureza

Cientistas

Viagens

Expediçũes

Instituiç̃̃es

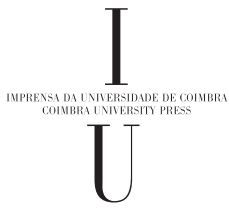

- colmbra 2006 
(Página deixada propositadamente em branco) 


\section{Paulo Cunha}

Mestrando na Faculdade de Letras da Universidade de Coimbra e Colaborador do Centro de Estudos Interdisciplinares do Século XX da Universidade de Coimbra, Portugal

\section{O Cinema Ao SERViço da CiênCia}

\section{Introdução}

Esta apresentação pretende revisitar o percurso do cinema científico em Portugal e tentar estabelecer pontos de contacto com todos os elementos contextuais que possam ter influenciado a maneira de ver e entender, através de uma linguagem muito peculiar, a evolução do pensamento científico no nosso país durante o último passado. Apoiado pelo panorama internacional do cinema científico, nomeadamente a partir do pioneiro e dinâmico modelo francês, tentou-se traçar em breves linhas gerais as principais características da produção e divulgação de filmes científicos portugueses. Não se ignorou a importância dos aspectos políticos e institucionais (que condicionaram a produção) e das ideologias e valores sociais (que influenciaram a divulgação) que marcaram o século XX português, nomeadamente a sua influência na produção cultural e na criação cinematográfica em particular.

No contexto internacional, os primeiros passos do cinema científico deram-se simultaneamente em duas direcções: enquanto método de investigação científica e enquanto agente de difusão científica e da acção educativa. Por um lado, a realização de importantes experiências nunca teria sido possível sem o contributo das emergentes novidades tecnológicas como a fotografia e o cinema, que passaram a ser consecutivamente aproveitadas e utilizadas com fins científicos, contribuindo significativamente para a realização de estudos até então impossíveis devido a insuficiências humanas. Por outro lado, os primeiros sinais oficiais do interesse dos pedagogos pelo cinema surgem em França, onde o governo patrocina diversas iniciativas e onde se realizaram um conjunto significativo de congressos nacionais e internacionais

\section{O filme científico português}

Ao longo dos tempos, o filme científico tem angariado diversas classificações e tipologias que variam conforme os seus autores. Apesar de ser um género específico dentro do cinema, o cinema científico tem sido alvo de várias definições imprecisas e algumas incorrecções na sua avaliação. Aceitam-se - na generalidade, mas com alguns apontamentos - as classificações que Luís de Pina produziu, em vários estudos, para o filme científico português. 
O conhecedor crítico definiu por critérios técnicos (desde a metragem à produção), os "Cinemas Especializados", incluindo nessa classificação todo o tipo de prática fílmica considerada marginal ao cinema de fundo ficcionado: o cinema didáctico e cultural, o cinema de animação, o cinema publicitário e turístico, o cinema televisivo, o cinema de amadores e o filme técnico e científico. Por sua vez, o género «filme técnico-científico» engloba o filme agrícola, o filme técnico-industrial, o filme de trabalho, o filme militar e o filme científico. ${ }^{1}$

O filme científico não é uma designação de fácil trato, pois a especificidade que este género alcançou em alguns países da Europa (como a França ou Inglaterra), e que foi decisiva na sua afirmação genérica, raramente foi conseguida em Portugal. Contudo, a designação filme científico, no particular contexto português, é usada neste estudo para caracterizar todas as obras que abordem qualquer tipo de fenómeno ou temática científica. Independentemente dos objectivos ou da origem, considerou-se neste estudo como filme científico todo aquele que aborda, de forma directa ou indirecta, as mais variadas temáticas científicas.

\subsection{Os períodos de produção}

\section{a) Os primeiros filmes (1912-1930)}

Segundo os dados mais recentes, o primeiro filme científico português foi rodado em 17 de Abril de 1912, quando o professor Costa Lobo registou cinemato-graficamente o Eclipse do Sol em Coimbra, enquanto noutras localidades do país se registava simultaneamente $O$ Eclipse do Sol em Lisboa, da produtora Lusa Film, e O Eclipse de Sol em Ovar, de autoria desconhecida.

Nesta fase embrionária, o cinema português apenas se limitava a uma função reprodutora, tendo sempre em atenção aquilo que se ia produzindo no estrangeiro, designadamente em França. $\mathrm{O}$ teor destes filmes era meramente descritivo, assumindo o carácter de reportagem de actualidade ou de filme turístico, longe das pretensões científicas assumidas internacionalmente e de alguns projectos originais para o cinema científico. Ao contrário do experimentalismo que se ia efectuando em França e nos Estados Unidos na procura de novas soluçōes técnicas para aplicações do cinema às necessidades específicas das diversas práticas científicas, em Portugal o filme científico conhecia uma expressão insignificante, tanto a nível técnico como estético.

\section{b) Durante o Estado Novo: o controlo estatal (1930-1960)}

O cinema foi uma das expressões estéticas utilizadas pelo aparelho propagandístico do Estado Novo. Empenhado numa estratégia de propaganda política e social, o

\footnotetext{
${ }^{1}$ Luís de Pina, «Os Cinemas Especializados». In: Aventura do Cinema Português, Lisboa, Editorial Vega, 1977, pp. 138-150; e "Cultura e Informação». In: Panorama do Cinema Português, Lisboa, Terra Livre, 1978, pp. 68-74.
} 
aparelho oficial encetou diversas campanhas que visavam mostrar ao cidadão comum os benefícios do estado corporativo, entre os quais o desenvolvimento dos cuidados de saúde e de assistência social eram de uma importância capital.

Entre os principais organismos públicos apoiados por serviços cinematográficos contam-se: Secretariado de Propaganda Nacional/Secretariado Nacional de Informação, Ministério da Agricultura (Campanha do Trigo), Ministério da Saúde (Direcção-Geral de Saúde), Ministério da Educação (Instituto de Meios Audio-Visuais de Ensino, Instituto de Tecnologia Educativa, Campanha Nacional de Educação de Adultos, Fundação Nacional de Alegria no Trabalho), Ministério das Corporações (Junta de Acção Social), Serviços Cartográficos do Exército, entre outros.

É igualmente significativa a produção de legislação atenta ao fenómeno cinematográfico e o desenvolvimento do debate em torno da questão do cinema educativo. O debate acerca das potencialidades educativas do cinema começara cedo mas, contudo, só em 1932 esse debate chegou à praça pública e ao interesse político.

No entanto, apesar da produção ser dominada pelas instituições ou organismos públicos, não se pode ignorar a intervenção de alguns agentes privados que patrocinaram ou protagonizaram a produção de filmes científicos das mais diversas áreas: desde o Grémio Nacional dos Industriais de Especialidades Farmacêuticas à Shell Portuguesa, com filmes destinados sobretudo a fins publicitários; ou então as diversas empresas cinematográficas nacionais e internacionais da época, que apostam decisivamente em filmes com objectivos declaradamente comerciais, apostando na exploração da curiosidade dos espectadores.

Este surto da actividade de mecenato, originário em algumas empresas da área da saúde mais atentas aos fenómenos do marketing e da auto-promoção, assumiu diversas formas de intervenção: o financiamento directo (encomendas); a concessão de subsídios de apoio à produção; ou as frequentes co-produçôes com entidades públicas ou empresas audiovisuais. De qualquer modo, estas iniciativas reconheciam uma invulgar capacidade de comunicação ao cinema.

Com maior interesse e relevância, verifica-se a persistência de alguns indivíduos independentes que, apesar das evidentes dificuldades técnicas e financeiras, continuam a produzir interessantes obras de divulgação, como os filmes amadores do engenheiro Carneiro Mendes e do médico António de Menezes.

Neste período, a proliferação de uma produção cultural de inspiração progressista (filiada em movimentos de pendor libertário, anarquista ou comunista) atribui uma grande importância à divulgação científica, incentivando e valorizando a aplicação das diversas expressões artísticas ao serviço cívico e cultural.

\section{c) A nova geração cinéfila (1960-80)}

Portugal assiste, em Dezembro de 1957, ao primeiro Festival do Filme Científico, organizado pela Sociedade Portuguesa de Ciências Naturais, que contou com a presença do prestigiado Jean Painlevé. Os filmes exibidos, todos de origem estrangeira, foram fornecidos pela Shell e pelo Instituto Britânico. Apesar de alguns eventos significativos em Portugal, o desenvolvimento do cinema científico continuava a denotar muitas dificuldades a nível da produção. 
Nos anos 60, iniciava-se em Portugal um significativo desenvolvimento da produção cinematográfica médica aplicada à investigação. Realizaram-se várias experiências na Faculdade de Medicina de Lisboa, nos Hospitais Clínicos de Lisboa e no Serviço de Cinema da Faculdade de Farmácia do Porto.

Simultaneamente, a recém-criada televisão pública passava a ter uma intervenção significativa no processo de produção e divulgação do panorama audiovisual português. No decorrer dos anos 60, o projecto Televisão Educativa (mais conhecido como "Telescola»), criado no âmbito dos trabalhos do Instituto dos Meios Audio-Visuais de Ensino, foi uma importante experiência de sensibilização que contou com a colaboração de diversos cineastas.

A par destas iniciativas de instituições oficiais, verificam-se importantes acções de mecenato na produção de filmes científicos. O crescimento da produção privada, relacionado com o desenvolvimento da publicidade, permitia prestigiar as instituiçóes promotoras. O mais significativo foi o caso da farmacêutica Merck Sharp \& Dohme que entre 1972-79 produziu quinze filmes sobre diversos temas relacionados com Medicina e Farmácia.

\section{d) Os últimos anos: os festivais e a televisão (1980-2000)}

Na década de 80 , a produção dos filmes científicos deu um passo atrás em relação ao surto quantitativo das décadas anteriores. As temáticas actuais reflectem as novas preocupações de um mundo em plena transformação, ajudando a compreender melhor os novos paradigmas e potencialidades da ciência e promovendo a ecologia.

Progressivamente, à medida que se afastou do grande público, a produção do filme científico foi-se confinando a uma espécie de "gueto académico». O que se verifica nos últimos anos é que o filme científico tem sido remetido para os festivais da especialidade (CineCiência, TeleCiência, FilmÓbidos), concentrados temporal e geograficamente, ou então para os canais temáticos da televisão por cabo, com acesso restrito a uma minoria da população (Discovery Channel, Odisseia e National Geographic, TV Saúdel TV Medicina e Farmácia TV).

O cinema científico tornou-se uma actividade esporádica e de difícil acesso ao grande público, factores que determinam negativamente, nestes últimos anos, o lento desenvolvimento deste género cinematográfico em Portugal. Os principais interessados na divulgação e expansão do cinema científico têm insistido frequentemente na urgência de uma intervenção estatal, quer na intensificação de articulação entre os diversos organismos públicos, nomeadamente as várias instituições de ensino e investigação e a televisão pública, quer no fomento de mecanismos de financiamento e divulgação.

\section{Conclusões}

A principal conclusão é evidente: não se pode considerar que tenha existido uma frequente e intensiva prática cinematográfica dedicada aos filmes científicos. Pelo contrário, pode-se afirmar que a produção de filmes científicos portugueses é pouco significativa no desenvolvimento da nossa cinematografia. O corpus que constitui a 
base deste estudo é composto por filmes resultantes de uma produção visivelmente esporádica e sem grandes consequências, representando apenas pouco mais de $2 \%$ da produção fílmica portuguesa. Devido a sérias dificuldades de ordem técnica e operacional, que facilmente se justificam, o filme científico nunca teve grande impacto no mercado cinematográfico nacional. Algumas experiências isoladas não são suficientes para se poder falar de um cinema científico, embora se registe, com alguma frequência, actividades deste género em algumas instituiçóes públicas ou privadas, datadas curiosamente em épocas muito específicas.

Partindo de uma análise quantitativa, pode-se constatar que, quanto à origem da produção, existe um acentuado desequilíbrio entre as obras produzidas por iniciativa pública $(34 \%)$ e por iniciativa privada $(59 \%)$. Em relação à finalidade da produção, verifica-se uma clara vantagem dos filmes de divulgação ou informação (38\%), seguidos de um equilíbrio entre os filmes de carácter comercial ou publicitário (23\%) e os filmes de investigação e divulgação científica (24\%). Relevante, mas por defeito, é a escassa produção de filmes educativos (11\%), obras destinadas a actividades de ensino, quer seja ensino técnico, superior, básico ou de adultos.

Ao atender-se a uma divisão temática do corpus, ressalta desde logo o volume de filmes dedicado à assistência médica e social (40\%), graças à prolífera produção oficial característica do período estadonovista. Também é significativo o número de filmes dedicados a assuntos médicos (24\%) e a assuntos ambientais e ecológicos (17\%).

Inicialmente destinados aos complementos cinematográficos, a divulgação deste género fílmico sofreu transformações determinantes na evolução da produção. A progressiva marginalização na divulgação, remetida para festivais da especialidade e para a televisão de sinal fechado, prejudicou decisivamente o desinvestimento verificado a partir da década de 80. A manifesta falta de garantias de divulgação dos filmes científicos condiciona, desde logo, a própria produção.

Em suma, nesta época de crise das ideologias, em que a ciência constitui um valor de referência na compreensão do mundo, "o filme científico de divulgação pode contribuir para o desenvolvimento de uma cultura científica e esta para a redução de conflitos de interesses que venham a manifestar-se entre o individual e o social, o individual e o político. Estes podem diluir-se com o desenvolvimento de uma cultura científica, uma vez que a compreensão da ciência e da tecnologia é útil para todos os que vivem numa sociedade.» ${ }^{2}$

2 José Ribeiro, "As Imagens da Ciência», 1993, Recensio, Revista de Recensões de Comunicação e Cultura - Universidade da Beira Interior, /http://www.recensio.ubi.pt, 24-XI-02. 


\section{Colecçãa \\ 2 Ciências e Culturas Caimbra 2006}

